\title{
PERANCANGAN SISTEM INFORMASI SERVIS MOTOR PADA BENGKEL ARIF MOTOR
}

\author{
Beby Rohmah Udmi Annidah', Lukas Arief Prasetyo ${ }^{2}$, Puji Astuti \\ Program Studi Teknik Informatika, Fakultas Teknik dan Ilmu Komputer, \\ Universitas Indraprasta PGRI \\ Jalan Raya Tengah No 80, Kelurahan Gedong, Pasar Rebo, Jakarta Timur \\ bebyrohmahudmiannidah@gmail.com ${ }^{1}$, lukasariedprasetyo@gmail.com², poetie12@gmail.com ${ }^{3}$
}

\begin{abstract}
Abstrak
Bengkel atau lokakarya adalah sebuah bangunan yang menyediakan ruang dan peralatan untuk melakukan konstruksi atau manufaktur, dan memperbaiki benda. Bengkel Arif Motor merupakan bengkel perawatan, perbaikan dan penjualan yang harus selalu memberikan pelayanan yang optimal bagi pelanggannya. Dalam, melakukan transaksi dan pencatatan servis motor sering terjadi human error yang karena masih dilakukan secara manual dan sulitnya proses transaksi penjualan sparepart karena media pencatatn yang digunakan masih memakai media kertas. Sehingga, perlu adanya suatu aplikasi sistem informasi servis bengkel, aplikasi ini dibuat guna membantu kinerja pegawai dalam membuat bukti traksaksi pelanggan, mempermudah admin dan kasir untuk memasukkan berbagai data servis dan sparepart dengan cepat, tepat dan akurat serta dapat membuat laporan kapanpun untuk kepala bengkel tanpa harus mencari atau mengumpulkan nota satu per satu. Metode penelitian yang ini yaitu menggunakan metode Grounded Research yaitu metode yang berdasarkan pada fakta dan menggunakan analisis perbandingan dalam menetapkan konsep serta mengembangkan teori. Tujuan dengan adanya aplikasi ini nantinya akan memudahkan dalam pengolahan data pembuatan laporan.
\end{abstract}

Kata Kunci : Sistem Informasi, Service Motor, Bengkel, Java

\begin{abstract}
A workshop or workshop is a building that provides space and equipment to do construction or manufacturing, andrepairs objects.. Arif Motor Workshop is a maintenance,, repair and sales workshop that must always provide optimal service for its customers. In, conducting transactions and recording of motorcycle services often occur human error because it is still done manually and the difficulty of the transaction process of selling sparepart because the registrar media used is still using paper media. So, it is necessary to have an application of workshop service information system, this application is made to help employees performance in making proof of customer transactions, make it easier for admins and cashiers to enter various service data and spare parts quickly, accurately and accurately and can make reports at any time for the head of the workshop without having to search or collect notes one by one. This research method is using Grounded Research method which is a method based on facts and using comparison analysis in establishing concepts and developing theories. Purpose in existence of this application will facilitate in the processing of data making reports.
\end{abstract}

Keywords: Information System, Motor Service, Workshop, Java

\section{PENDAHULUAN}

Pada era teknologi seperti sekarang ini, peranan komputer sangatlah diperlukan diberbagai bidang, baik instansi maupun perusahaan Hal ini disadari mengingat kebutuhan akan informasi yang menuntut cepat dan akurat terbukti dengan banyaknya perusahaan yang menggunakan sistem komputer yang dilengkapi aplikasi yang berguna untuk memudahkan pekerjaan agar lebih cepat, efektif dan efisien. Menurut (Marakas \& O'Brien, 2016) Sistem Informasi (SI) adalah kombinasi dari orang-orang, perangkat keras, perangkat lunak, jaringan komunikasi, sumber daya data, dan kebijakan serta prosedur dalam menyimpan, mendapatkan kembali, mengubah, dan menyebarkan informasi dalam suatu organisasi. Terbukti dengan banyaknya instansi dan perusahaan yang telah menggunakan komputer yang dilengkapi dengan aplikasi-aplikasi yang berguna untuk memudahkan pekerjaan agar lebih cepat, efektif dan efisian. sehingga menjadi suatu informasi yang dimanfaatkan oleh berbagai kalangan yang membutuhkannya. Salah satunya dalam proses transaksi penjualan sparespart sebuah bengkel karena dapat mempermudah kinerja pegawai dalam 
memaksimalkan proses pendataan service motor itu sendiri. Melihat kebutuhan dan situasi Bnegkel Arif Motor yang masih dilakukan secara manual yang rentan terjadi kesalahan dalam pencatatan. Sehingga, perlu adanya suatu Sistem Aplikasi Informasi Layanan Service, aplikasi ini dibuat guna membantu kinerja pegawai dalam hal penyewaan sehingga tidak banyak buku yang dikeluarkannya untuk pencatatan sehingga dapat membantu dalam membuat laporan yang tepat dan akurat serta untuk membantu mengendalikan proses layanan servis Bengkel Arif Motor. Berdasarkan latar belakang di atas, maka peneliti memberikan solusi kendala-kendala pada proses pengolahan data service motor, yaitu dengan merancang sistem aplikasi service serta pengeluaran sparepart yang dapat membantu proses keakuratan data service serta membuat suatu sistem pengolahan data sparepart dan jasa service yang dapat digunakan untuk meningkatkan kinerja pelayanan. Tujuan penelitian ini berdasarkan permasalahan diatas, maka peneliti mendapatkan gambaran tentang sistem yang sedang berjalan dan mengetahui masalah yang dihadapi sebagai acuan pembuat sistem yang lebih efektif dan efisien, merancang aplikasi service motor sebagai fasilitas yang dapat membantu proses penjualan sparepart, persediaan sparepart, dan jasa yang digunakan untuk service dan mengimplementasikan sistem dengan menggunakan data yang ada pada bengkel. Penelitian ini diharapkan dapat manfaat bagi Bengkel Arif dalam mendapatkan sistem baru yang lebih efektif dan dapat memudahkan mengolah data-data yang dibutuhkan dengan cepat dan akurat, dab memudahkan karyawan Bengkel Arif dalam mencatat, membuat transaksi serta laporan bulanan.

\section{PENELITIAN RELEVAN}

Dalam rangka mendapatkan hasil penelitian yang baik, selain melakukan penelitian secara langsung peneliti juga melakukan kajian pustaka. Dari hasil penelitian yang telah dilakukan. Beberapa hasil acuan yang menjadi acuan adalah:

Penelitian dari (Zarnelly, Aulil Amri, Nesdi Evrilyan Rozanda, 2018) yang berjudul "Rancang Bangun Sistem Informasi Pelayanan Customer PT. RJA Pekanbaru". Penelitian ini menghasilkan sebuah Sistem Informasi Layanan Customer berbasis web. Metode pengembangan yang digunakan adalah Waterfall Model dengan lima tahap: analisa sistem, perancangan sistem, coding, implementasi dan pengujian, serta operasi dan pemeliharaan. Dengan Sistem Informasi Layanan Pelanggan berbasis Web diharapkan dapat memberikan layanan optimal dan memudahkan pelanggan dalam melakukan servis, membantu pimpinan untuk melihat stok suku cadang dan pelaporan.

Penelitian dari (Meta Litasari Sestiayunda, 2017) yang berjudul "Pengembangan Sistem Informasi Booking Service Motor Honda Pada PT.Pasific Motor II Bekasis Berbasis Web”. Dengan adanya program aplikasi ini diharapkan dapat membantu masyarakat agar lebih mudah mendapat informasi dan melakukan booking service. Perancangan program booking service ini dimulai dari pembuatan desain program berupa desain Entity Relationship Diagram dengan lima tabel pendukung, beserta Logical Structur Record, Struktur Navigasi yang terdiri dari admin dan pengunjung, sampai pengujian program yang dilakukan untuk menyesuaikan aplikasi apakah mudah digunakan atau tidak berdasarkan preferensi dari responden.

Penelitian dari (Sumardi, 2015) yang berjudul "Sistem Akutansi Penjualan Sparepart Dan Pelayanan Servis Sepeda Motor Pada CV.Area Motor Kudus". Metode pengembangan sistem yang digunakan untuk membangun Sistem Akutansi Penjualan Sparepart dan Pelayanan Servis Sepeda Motor di CV. Area Motor Kudus adalah waterfall yaitu Analisis, Desain, Implementasi, dan Evaluasi.

Penelitian dari (Siswandi, 2017) yang berjudul "Aplikasi Sistem Informasi Pembayaran Jasa Service Motor Dan Penjualan Sparepart Pada Bengkel Motor Berbasis Visual Basic 6.0". Dari hasil penelitian ini, peneliti akan merancang sebuah sistem informasi yang dapat mengolah data pelayanan service, penjualan dan pembelian yang diharapkan dapat memudahkan dalam mengolah data dan mengurangi kesalahan dalam pembuatan laporannya dan dalam penyampaian informasi data stock barang lebih cepat.

Penelitian dari (Ngurah Suryantara, 2014) yang berjudul "Rancang Bangun Aplikasi Reservasi Service Untuk Bengkel Sepeda Motor Berbasis Web". Penelitian ini membangun sebuah aplikasi reservasi service untuk bengkel sepeda motor berbasis web. Aplikasi ini dibangun dengan bahasa 
pemrograman PHP dan database MySQL yang telah didukung web responsive design. A.

Penelitian dari (Nugroho, 2015) yang berjudul "Sistem Informasi Pelayanan Jasa Servis Sepeda Motor Studi Kasus : Naga Mulya Motot Yogyakarta". Pada penelitian ini dibuat sebuah sistem informasi untuk memvisualisasikan status sepeda motor yang diservis. Hasil penelitian berupa sebuah sistem yang dapat memvisualisasikan status sepeda motor yang sedang diservis sehingga pelanggan yang berada di ruang tunggu mengetahui apakah sepeda motor yang di servis telah selesai.

Penelitian dari (Aera Santiana, 2018) yang berjudul "Sistem Informasi Pelayanan Jasa Service Pada Bengkel Cipta Prima Motor Cibitung". Penelitian ini membangun sebuah sistem informasi untuk membantu kasir dalam melayani pelanggan saat service kendaraan. Metode pengembangan dan penelitian ini adalah SDLC dengan model waterfall dan disertai dengan analisis SWOT serta analisa kelayakan TELOS. Hasil dari perancangan ini diharapkan dapat dibangun sistem informasi pelayanan jasa service yang mampu melayani pelanggan dengan cepat dan akurat.

Penelitian dari (Rohnadi, 2019) yang berjudul "Perancangan Sistem Informasi Menejemen Bengkel Di Gama Auto Service". Penelitian ini bertujuan untuk memberikan analisa kebutuhan Sistem Informasi proses kerja Divisi Servis di Bengkel Gama Auto Service. Memberikan konsep rancangan Sistem Informasi Manejemen proses kerja Divisi Servis di Bengkel Gama Auto Service. Hasil analisa data dirumuskan perancangan sistem informasi tentang informasi proses kerja mekanik kepada servis advisor, informasi penggantian suku cadang kepada servis advisor dan admin suku cadang, informasi tambahan pekerjaan mekanik kepada servis advisor.

\section{METODE PENELITIAN}

Metode penelitian yang digunakan untuk melakukan penelitian adalah metode grounded (grounded research). Menurut (Sugiyono, 2013) Metode Grounded Research yaitu suatu metode penelitian yang berdasarkan generasi empiris, menetapkan konsep, membuktikan teori, mengembangkan teori, mengumpulkan dan analisis data dalam waktu yang bersamaan. Setelah mengumpulkan data, peneliti melanjutkan proses penelitian sesuai dengan langkah-langkah pokok yang digunakan pada metode ini, yaitu menentukan masalah yang ingin diselidiki, mengumpulkan data atau informasi yang ada di lapangan, menganalisis dan menjelaskan masalah yang ditemukan serta membuat laporah hasil penelitian. Metode pengumpulan data yang digunakan Peneliti untuk mendapatkan data dan informasi yang mendukung penyempurnaan hasil dari penelitian ini antara lain:

1. Studi Kepustakaan

Pengumpulan data dan informasi dari kutipan buku-buku literatur, serta hasil laporan dan bahan lainnya yang berkaitan dengan penelitian ini. Dari bahan-bahan tersebut diambil teori-teori yang dapat dijadikan landasan untuk menganalisa masalah yang ditemukan dalam penelitian.

2. Studi Lapangan dilakukan dengan melihat langsung penerapan proses produksi dan pemensanan, dalam studi lapangan ini dipergunakan teknik pengumpulan data antara lain dengan cara:

a) Wawancara

Teknik pengumpulan data dengan cara bertanya kepada pelaksana atau pemilik yang terlibat langsung dalam kegiatan proses transaksi dari Bengkel Arif Motor.

b) Observasi

Peneliti melakukan survei atau observasi untuk mengamati secara langsung proses transaksi dan pengolahan data yang dilakukan oleh Bengkel Arif Motor.

c) Sumber Data

Pengumpulan data dan informasi yang dilakukan dengan cara mengamati langsung ke objek dan juga menganalisa sistem yang sedang berjalan, serta mengamati langsung sistem transaksi online yang sudah ada di internet.

\section{HASIL DAN PEMBAHASAN}

Alternatif penyelesaian masalah yang akan peneliti buat adalah dengan membuat sistem informasi Bengkel secara terkomputerisasi, untuk mempermudah dalam proses pengolahan data dan laporan. Sistem informasi ini akan dibuat dengan menggunakan bahasa pemrograman Java Netbeans dan 
menggunakan databaseMySQL. Data dari proses pengolahan data servis dan sparepart ini akan disimpan dalam database. Dengan penyimpanan data pada database ini diharapkan mampu mempermudah dalam proses pencarian data dan adanya laporan setiap bulannya sehingga laba perusahaan dapat terlihat dan termanagement. Pembuatan laporan juga akan dirasa cukup mudah karena pengguna tinggal mencari data yang dibutuhkan dalam file-file yang ada di komputer. Proses perhitungan data-data pelanggan yang servis dan penjualan sparepart yang cukup banyak akan lebih mudah dikerjakan dengan sistem informasi ini. Sistem informasi ini dibuat semudah mungkin dalam proses pengoperasiannya, sehingga pengguna tidak begitu kesulitan untuk memahami dan mempelajari proses pengoperasiannya

\section{Diagram Alir Data (DAD) Sistem yang Diusulkan (Diagram Konteks, Nol, Rinci) Diagram Konteks}

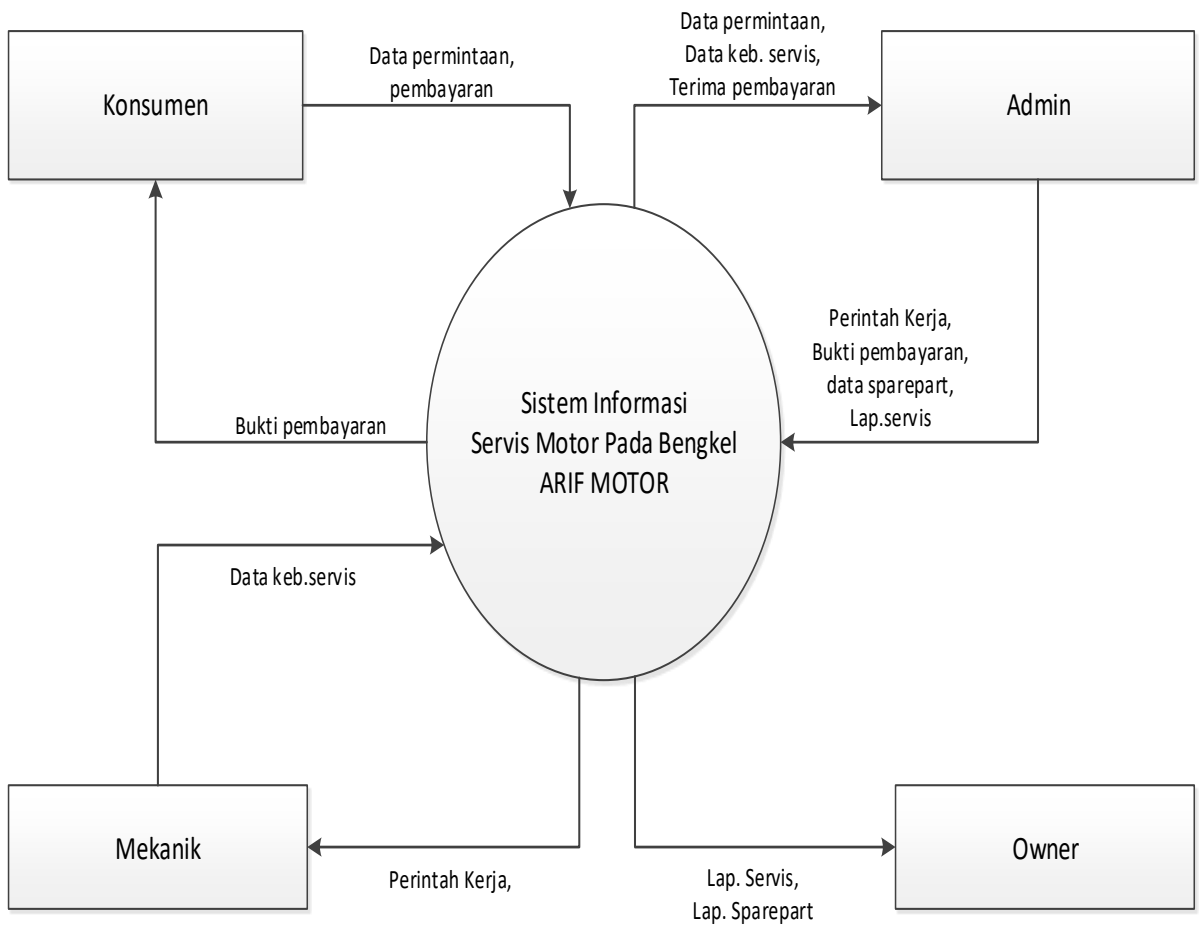

Gambar 1 . Diagram Konteks Yang Diusulkan

Pada diagram diatas memperlihatkan gambaran umum dari subsistem rancang bangun sistem informasi servis motor di bengkel arif motor, karena seluruh subsitem hanya diwakili oleh satu simbol proses. Subsitem aplikasi informasi servis motor bengkel, berinteraksi dengan kesatuan luar atau kelompok pengguna yaitu konsumen, admin, mekanik dan owner. Konsumen memberikan data permintaan dan melakukan pembayaran setalah mendapatkan layanan service serta menerima bukti pembayaran. Admin bisa mengakses semua data permintaan, service, terima pembayaran. Admin juga membuat semua laporan dari sistem servis motor. Mekanik mendapatkan perintak kerja yang diberikan admin, memeriksa motor customer dan memberikan data service motor konsumen, Owner dapat melihat seluruh laporan dari sistem informasi servis motor 


\section{Entity Relationship Diagram (ERD)}

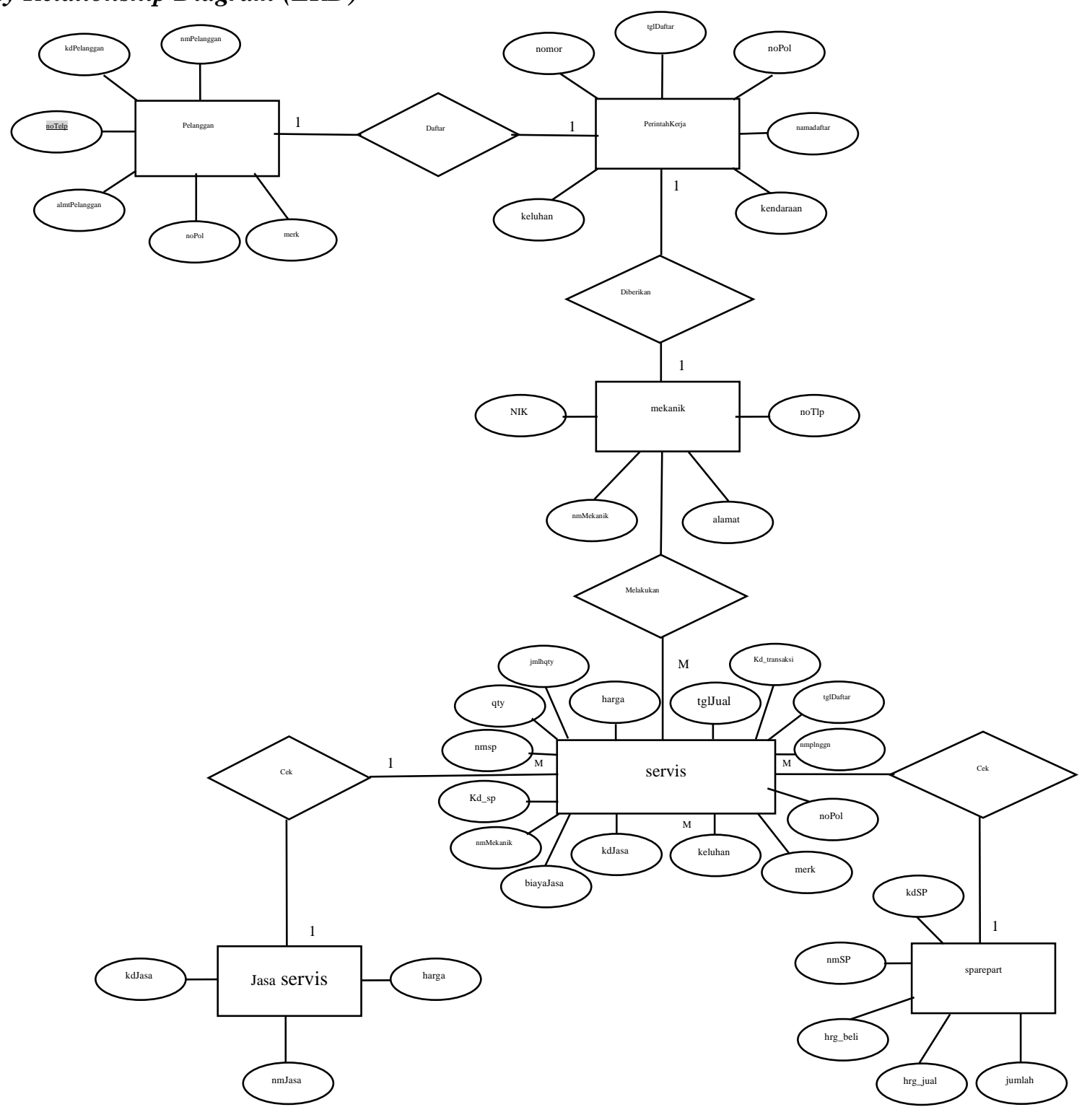

Gambar 2. ERD (Entity Relationship Diagram)

Pada gambar diatas dapat dijelaskan bahwa pelanggan mendaftar untuk melakukan service motor serta memberikan informasi permasalahan motor untuk dilakukan service. Mekanik mendaptkan surat perintah kerja yang diberikan admin yang beriiskan data-data permasalaha pelanggan, mekanik melakukan servis motor pelangggan. Service dilakukan dengan pengecekan seluruh motor dan apalabila ada sparepart yang harus diganti, mekanik akan melaporkan ke admin dan admin akan sampaikan ke pelanggan terkait permasalahan motor pelanggan 


\section{Rancangan Tampilan Layar}

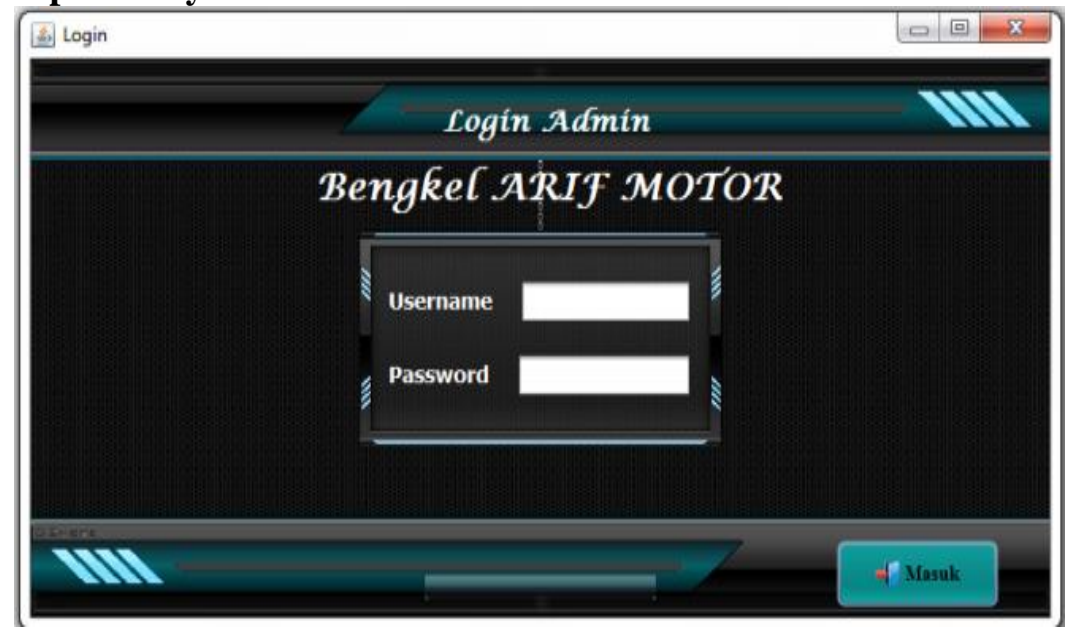

Gambar 3 . Tampilan Menu Login

Tampilan Login admin digunakan sebagai kata kunci sebelum kita memasuki menu admin. Agar tidak semua orang dapat mengakses program ini. Sehingga dalam form menu kerahasiaannya tetap terjaga dengan baik. Apabila pengguna dapat memasukkan username pengguna dan password dengan tepat.

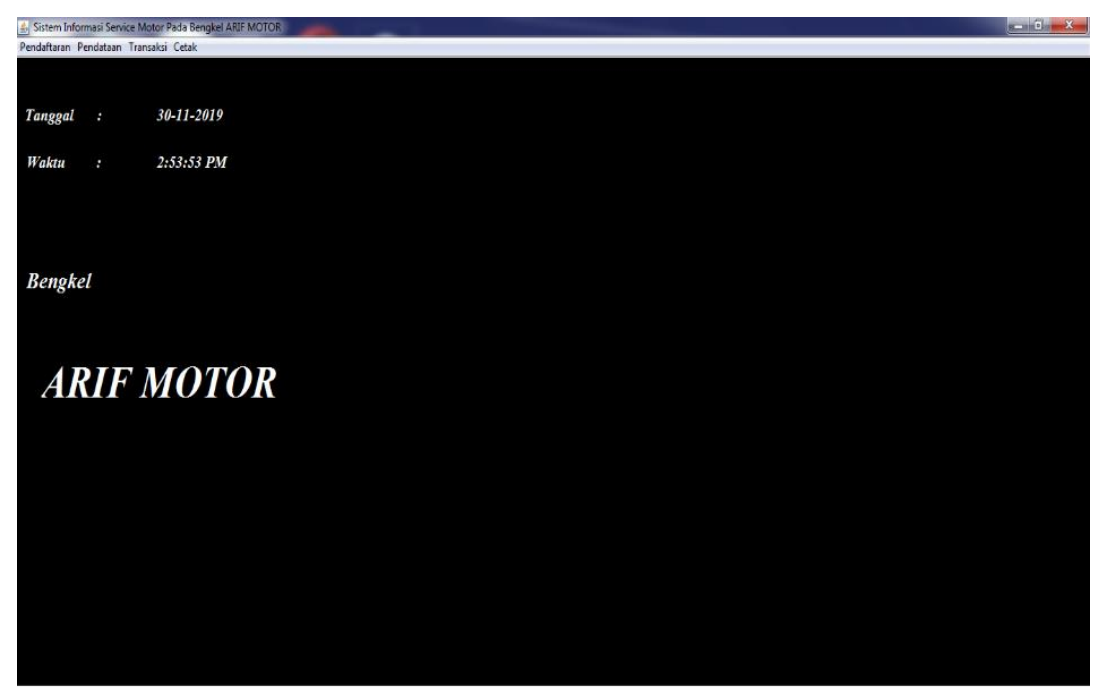

Gambar 4. Tampilan Menu Utama

Tampilan layar di atas menampilkan tampilan menu utama sistem informasi Servis Motor pada bengkel Arif Motor. Menu utama yang berfungsi untuk melihat data Master (Data Sparepart, Jasa Servis, Mekanik, dan data Pelanggan), data Transaksi Servis maupun penjualan Sparepart, serta rekap data Sparepart setiap bulannya dan rekap data transaksi setiap harinya. 


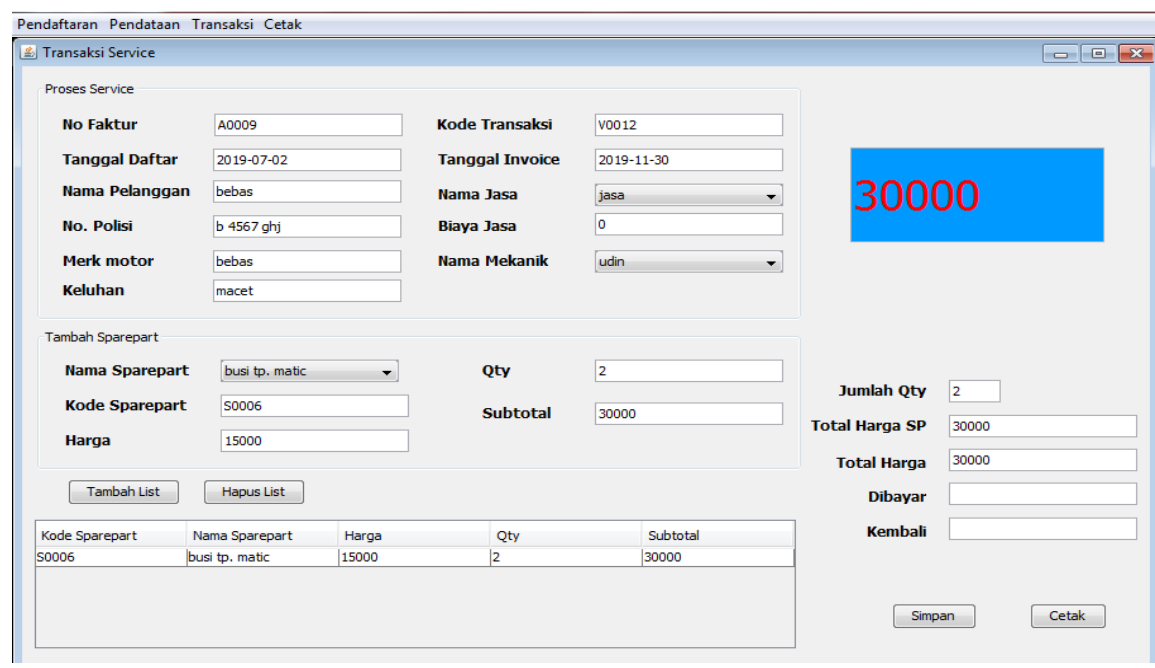

Gambar 5. Tampilan Transaksi Servis

Menu ini berguna untuk mengolah transaksi servis yang sebelumnya telah didaftarkan pada menu perintah kerja yang akan dijadikan bukti pembayaran atau transaksi yang terjadi pada bengkel Arif Motor.

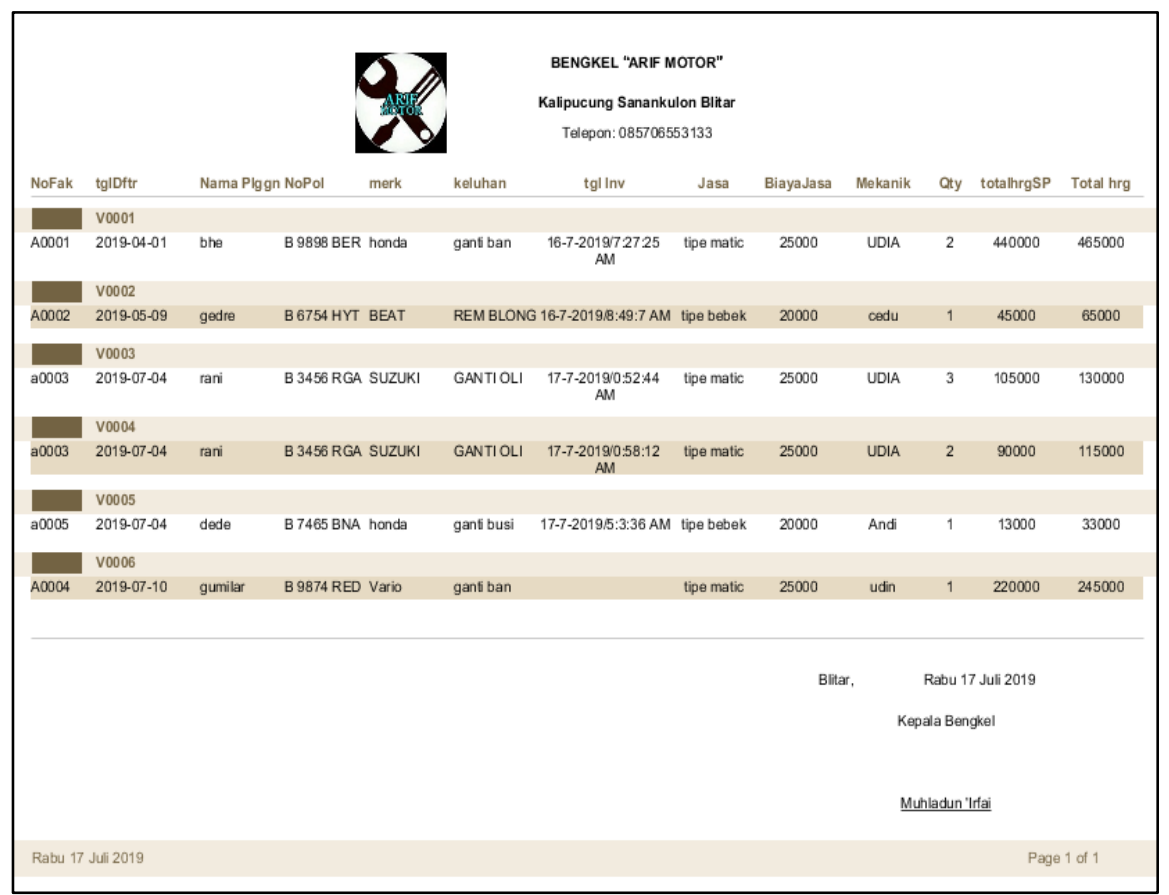

Gambar 6. Tampilan Laporan Transaksi Service

Laporan ini dapat dilihat laporan keseluruhan Transaksi service untuk laporan kepada kepala bengkel setiap harinya.

\section{SIMPULAN}

Dari hasil pembahasan yang telah diuraikan pada bab-bab sebelumnya, maka dapat disimpulkan bahwa dengan adanya Sistem Aplikasi Informasi Service Motor Bengkel Arif Motor ini dapat memudahkan admin bengkel dalam melakukan pengolahan data servis motor yang ada di Bengkel Arif Motor. Dengan menggunakan Sistem Aplikasi Informasi Service Motor Bengkel Arif Motor ini dapat mengefisiensikan waktu serta mempermudah kinerja admin dalam melakukan pelayanan servis motor dan pembuatan laporan transaksi service. menggunakan Sistem Aplikasi Informasi Service Motor Bengkel Arif Motor ini dapat meminimalisir adanya kesalahan dalam pencatatan, pendataan transaksi. Dengan adanya Sistem Aplikasi Informasi Service Motor Bengkel Arif Motor 
ini, data-data yang disimpan lebih terstruktur dan juga lebih aman serta sistem menjadi lebih efektif dan efisien.

\section{DAFTAR PUSTAKA}

Aera Santiana, H. (2018). Sistem Informasi Pelayanan Jasa Service Pada Bengkel Cipta Prima Motor Cibitung. INFORMATION SYSTEM FOR EDUCATORS AND PROFESSIONALS, Vol.2, No., 201-214.

Marakas \& O’Brien, 2017). (2016). Analisa Sistem Informasi/ Tata Sutabri, Ed 1. Andy.

Meta Litasari Sestiayunda, F. P. H. (2017). PENGEMBANGAN SISTEM INFORMASI BOOKING SERVICE MOTOR HONDA PADA PT. PACIFIC MOTOR II BEKASI BERBASIS WEB. Jurnal Inkofar, Volume 1 N, 51-61.

Ngurah Suryantara, I. G. (2014). Merancang Aplikasi dengan VB.net2013. PT Elex Media Komputindo Kelompok Gramedia.

Nugroho, S. E. (2015). SISTEM INFORMASI PELAYANAN JASA SERVIS SEPEDA MOTOR Studi Kasus : Naga Mulya Motor Yogyakarta. Jurnal EKSIS, Vol 08 No, 50-58.

Rohnadi, D. (2019). Perancangan Sistem Informasi Menejemen Bengkel Di Gama Auto Service. Teknoin, Vol. 25, N, $112-125$.

Siswandi, A. (2017). APLIKASI SISTEM INFORMASI PEMBAYARAN JASA SERVICE MOTOR DAN PENJUALAN SPARE PART PADA BENGKEL MOTOR BERBASIS VISUAL BASIC 6.0. Jurnal Teknologi Pelita Bangsa - SIGMA, Vol. 6 No., 158-167.

Sugiyono. (2013). Metode Penelitian Kuantitatif dan $R \&$ D. Alfabeta.

Sumardi. (2015). SISTEM AKUNTANSI PENJUALAN SPAREPART DAN PELAYANAN SERVIS SEPEDA MOTOR PADA CV. AREA MOTOR KUDU. INFOKAM, Nomor II /, 96-105.

Zarnelly, Aulil Amri, Nesdi Evrilyan Rozanda, M. (2018). Rancang Bangun Sistem Informasi Pelayanan Customer PT. RJA Pekanbar. Seminar Nasional Teknologi Informasi, Komunikasi Dan Industri (SNTIKI-10), Pekanbaru, 107114. 